\title{
Mutações de Olhar: as vias de diálogo entre o campo e o arquivo
}

\author{
Marcelo Moura Mello \\ Mestrando em Antropologia Social na Unicamp. Bolsista Fapesp \\ mouramello@yahoo.com.br
}

\begin{abstract}
Resumo $\mathrm{O}$ objetivo deste artigo é refletir sobre o uso de fontes arquivísticas na pesquisa antropológica e sua relação com a produção etnográfica, bem como a implicação das experiências de campo sobre a descrição, manejo e leitura dessas fontes. $\mathrm{O}$ artigo expõe os diferentes contextos das pesquisas de campo e em arquivos históricos envolvendo a comunidade negra rural de Cambará, que fica localizada entre os municípios de Cachoeira do Sul e Caçapava do Sul (Rio Grande do Sul). Considera-se que somente tomando a oralidade em seus próprios termos - por meio da descrição das formas de lembrar e do trabalho da memória - é possível diminuir a assimetria entre oral e escrito. Argumenta-se também que os relatos orais coletados em campo podem exercer efeitos de conhecimento na leitura das fontes escritas e colocar novas questões para a reconstituição histórica do passado.
\end{abstract}

Palavras-chave: oralidade; relatos orais; arquivos; história; memória.

$\mathrm{T}$ OMANDO EM CONSIDERAÇão os diferentes contextos em que realizei, e venho realizando, pesquisas sobre a comunidade negra rural de Cambará - localizada entre os municípios de Cachoeira do Sul e Caçapava do Sul (RS) - o artigo discute o tratamento teórico e metodológico que pode ser dado à oralidade em sua interface com o escrito. Mais especificamente, pergunta-se pelos efeitos de conhecimento das experiências e encontros etnográficos da pesquisa de campo na relação estabelecida com o arquivo.

A referência a encontros e experiências não é fortuita. Ao iniciar uma pesquisa na comunidade acerca de cinco anos, tornava-se imperativo retornar ao passado. $\mathrm{O}$ grupo estava às voltas com o processo de reconhecimento para comunidade remanescente de quilombo, e a universidade desenvolvia ações para reforçar essa identidade (então) em irrompimento. O primeiro encontro com o arquivo resultou das situações práticas nas quais tal grupo se achava envolvido, direcionando o olhar ao pensar a conjugação dito/escrito.

À medida do tempo, outras questões foram se impondo, e os encontros deslocavam-se para patamares conformados pelas relações de conhecimento entretidas no correr da investigação. Relações de conhecimento estabelecidas por meio de distintas experiências etnográficas. Diferentes encontros com o passado transformam aquilo que pode se apresentar, aos nossos olhos, de forma acabada, em algo aberto, sujeito a novas leituras e possibilidades de entendimento. $\mathrm{O}$ olhar sobre a relação dito/escrito foi se modificando ao longo de minha pesquisa de mestrado. São essas mutações de olhar que pretendo reconstituir aqui. 
Para realizar esta proposta o artigo percorre o seguinte caminho: a primeira seção expõe o contexto das pesquisas em arquivos sobre a história da comunidade de Cambará. Esse primeiro encontro com o arquivo direcionou olhares sobre o material proveniente do campo e resultou em dilemas conceituais, teóricos e metodológicos. Na segunda seção relaciono os relatos orais dos integrantes do grupo às formas de lembrar e ao "trabalho da memória" (Godoi, 1999) existentes no local. Argumenta-se que somente pensando a oralidade em seus próprios termos é possível diminuir a assimetria entre oral e escrito. Por fim, retomo a problemática campo/arquivo perguntando pelos efeitos de conhecimento dos encontros e experiências de campo na relação estabelecida com o arquivo.

\section{Confirmação recíproca}

Nesse primeiro momento trago ao leitor (a) o contexto em que se deram as pesquisas em arquivos sobre a história de Cambará. Farei isso por meio de uma breve exposição dos projetos de pesquisa que ali tiveram lugar. Como veremos a seguir, a assunção identitária do grupo como comunidade remanescente de quilombo foi determinante para o caráter que as pesquisas - e os procedimentos investigatórios - assumiram.

Três projetos de extensão da Universidade Federal do Rio Grande do Sul (UFRGS) foram desenvolvidos em Cambará nos anos de 2002 e 2003. Os dois primeiros - ambos realizados no ano de 2002 - tiveram curta duração. A participação no último deles - que se desenvolveu em dez finais de semana entre os meses de setembro e dezembro de 2003 - permitiu minha inserção no grupo. Já nessa época os estudantes que participavam desses projetos tinham por incumbência, entre outras coisas, realizar entrevistas com os moradores e coletar dados que pudessem servir de base para a possível elaboração de uma perícia antropológica, doravante denominada "laudo".

De fato, o trabalho da UFRGS no local inseriase em um contexto mais amplo, em que a discussão de políticas públicas para os territórios negros no Rio Grande do Sul gradualmente ia assentando suas bases. Já em 2001, uma política do Governo do Estado do Rio Grande do Sul, madiante a Secretaria Estadual do Trabalho, Cidadania e Ação Social (STCAS), em convênio com a Fundação Cultural Palmares (FCP), aplicou recursos para a elaboração de relatórios técnicos (laudos) objetivando à identificação, reconhecimento, delimitação territorial, levantamento cartorial e a demarcação das terras que possibilitassem à titulação e o registro em cartório de registro de imóveis de comunidades remanescentes de quilombo.

Foram realizados laudos de cinco comunidades que reivindicavam a titulação de suas terras com base no artigo 68 do Ato das Disposições Constitucionais Transitórias ${ }^{1}$. Inicialmente, previa-se que Cambará seria contemplada pelo convênio. Limitações orçamentárias impediram a consecução do plano. Somente em 2005 a UFRGS, em convênio firmado com a Superintendência Regional do Instituto Nacional de Colonização e Reforma Agrária (Incra), começou a elaborar um laudo antropológico, com vistas a instruir o Incra nos procedimentos administrativos referentes a Cambará, que também reivindicava a titulação de suas terras com base no referido artigo 68. A UFRGS formou uma equipe que contou com professores e estudantes provenientes da Geografia, História e Ciências Sociais (equipe da qual eu fiz parte).

Foi nesse contexto de produção de um laudo que as pesquisas em arquivos se iniciaram. $\mathrm{O}$ fato de eu possuir um contato prévio com boa parte do grupo - detendo um conhecimento razoável dos eventos tidos por marcantes para os moradores do local - fez com que me envolvesse diretamente com as incursões aos arquivos desde o princípio. Supunha-se que seria possível localizar documentos que reportassem a esses eventos, o que ulteriormente se confirmou. Foi possível localizar em diversos arquivos farta documentação que reportava a muitos fatos narrados por homens e mulheres de Cambará. O dito e o escrito confirmavam-se, até mesmo em pormenores.

Ao longo do laudo, insistimos na tese da confirmação recíproca ${ }^{2}$. Foram três as principais razões que concorreram para o uso desta noção: a já aludida localização de diversos documentos que reportavam aos eventos tidos por marcantes e fundantes da história do grupo, o gênero específico de saber que estávamos produzindo e a valorização da oralidade como fonte.

$\mathrm{O}$ uso de relatos orais e documentos escritos ampliou o leque de possibilidades na reconstituição dos eventos pretéritos. Entretanto não se tratava apenas de um fato fortuito (embora riquíssimo) ou de um incremento de material empírico. Evidentemente que a interface entre oral e escrito alargava o conhecimento sobre o passado que estávamos reconstruindo. Contudo, o investimento nos arquivos estava diretamente condicionado ao gênero de saber que estávamos produzindo.

Ora, a peça que elaborávamos visava "reconhecer" direitos. Embora haja uma flexibilização crescente da legislação, sabe-se que há de percorrer caminhos tortuosos até que os direitos previstos na Constituição 
tenham plena efetividade. As narrativas dos moradores de Cambará por si só não eram uma garantia da validade do pleito. Passa-se algo diferente quando os relatos sobre o roubo de terras encontram equivalência no escrito. O estatuto das provas mortas incide poderosamente sobre os vivos.

Como notou Oliveira (2002, p.258), a intervenção de antropólogos em processos judiciais e administrativos deve ser tomada como exercício de uma competência técnico-científica em meio a um complexo jogo de pressões e negociações que envolvem diferentes agentes. Destarte, a busca e a localização de documentos esteve diretamente condicionada por essa situação prática. A confirmação recíproca necessitou ser construída e legitimada como conceito analítico. Estamos diante da constituição de um campo eminentemente político onde representações autorizadas sobre o presente e seus significados para diferentes atores estão particularmente sinalizadas e visíveis nos arquivos (Cunha, 2005). Se o passado é um campo de disputas, as mediações com os arquivos podiam oferecer ferramentas para "autorizar" os discursos e versões do passado.

E aqui as coisas começam a ficar interessantes. Até que ponto nosso objetivo de valorizar a oralidade não era minado por nossas próprias descrições, escolhas teóricas e opções metodológicas? Em que medida não tomávamos um atalho que desembocava nos mesmos labirintos? É realmente possível tomar a oralidade simetricamente quando ela nos interessa somente em face de sua correspondência com esse lugar da memória (Nora, 1984) que é o Arquivo? Será que uma descrição atenta aos jogos de poder não acaba por pacificar a memória (Fabian, 2007)? Ou, dito de outra forma, tomar essas memórias a partir de uma variável privilegiada não empobrece o mosaico que constitui o trabalho da memória?

Na situação de perícia, o papel e a competência que antropólogos são chamados a cumprir estão imersos em um campo de disputas. Os quesitos a serem respondidos são elaborados num contexto em que diversos agentes, investindo seus interesses e pré-concepções, dialogam (porventura pressionam) com o perito: a situação de perícia interfere na formulação e formatação das comunidades científicas e não-científicas (Anjos, 2005, p.111). Por maior que seja o rigor conceitual, analítico e ético investido neste tipo de intervenção, caberia perguntar se os efeitos de autoridade dos laudos não resultam na institucionalização de um estado do cenário das lutas sociais.

Destarte, ao enfatizar as confirmações recíprocas dos relatos em relação aos documentos escritos, não se estaria reforçando vozes fragilizadas ao custo da simplificação das formas de lembrar e do trabalho da memória em que esses relatos emergem? Ou seria possível explorar a oralidade em seus próprios termos, de modo a abrir outro espaço de interrogação aos saberes locais? Trabalho duplo este da perícia: explicitar as condições de possibilidade do fazer científico e facilitar a emergência de outras vozes e narrativas.

\section{Formas narrativas}

No próprio laudo investimos numa argumentação que visava corrigir a assimetria entre oral e escrito. $\mathrm{Na}$ confrontação entre ambas, chamamos atenção para as diferenças entre as versões dos fatos; fizemos um exercício inverso, perguntando não pela carência dos relatos, mas sim dos documentos; descrevemos os contextos e as formas de lembrar; em suma, tentamos tomar a oralidade em seus próprios termos. Como mencionei na seção anterior, esse exercício esteve preso a algumas amarras. Proponho nesse momento retomar os postulados da análise, antes de esboçar algumas idéias que não foram exploradas devidamente na perícia.

O primeiro postulado na confrontação entre dito e escrito consistiu em rechaçar a falácia que consiste em atribuir às fontes escritas "veracidade histórica" em detrimento da oralidade, marcada pela suposta imprecisão e vacuidade. Mesmo autores que tomaram esse cuidado incorrem em atitudes dúbias na avaliação das fontes, como no caso de Vansina (1985), por exemplo. Em que pese sua inegável contribuição para o estudo das tradições orais ${ }^{3}$, Vansina pende para uma avaliação delas ora segundo suas "limitações" ora para seu possível uso como fonte histórica:

Chronology and lack of independence are real problems for oral traditions. They can be overcome or alleviated in some cases by outside evidence, but because the contents of outside evidence tend no to be congruent with the contents of oral tradition such cases will remain the exception rather than the rule. One should still not give up hoping that outside sources will eventually be of assistance (Vansina, 1985, p.190).

As tradições orais podem desempenhar importante papel na reconstituição do passado, refinando e ampliando as possibilidades de reconstituição da história. Comparando o caso de Palmares com os estudos que realizou entre os Saramaka, no Suriname, Price (1996) aponta que ficar restrito às documentações escritas sobre povos historicamente vistos como ameaças restringe por demais a análise, podendo até mesmo incorrer em postulados parciais que limitam 
por demais a experiência histórico-social desses povos. O uso de evidências externas às tradições orais é válido e acresce substância na leitura e interpretação das mesmas ${ }^{4}$; o problema consiste no tipo de interface que é proposto.

Por essa razão argumentamos que a oralidade não deve ser avaliada em face ou em função do escrito, tampouco em razão de suas carências face ao escrito. A projeção é um dos mecanismos que causa a confusão entre juízo de relação e atributo do objeto (Goldman; Lima, 1999). A transposição para outro domínio de discriminações que operamos no nosso dia-a-dia e que têm suas raízes em nossos sistemas de valores alimenta a partilha entre oral e escrito, implicando assimetrias expressas em termos como ausência e presença (ausência e presença de cronologia, profundidade histórica, criatividade etc.). Este é o caso dos empreendimentos de Vansina (1985), Ong (1998) e Goody (1985; 1987). Sem negar a contribuição desses autores, não creio que preocupações que giram em torno da diferença entre "nós" e "eles" sejam o melhor caminho a ser seguido, especialmente quando avaliamos outros domínios a partir de uma antropologia das ausências ${ }^{5}$.

Como nota Fabian (2007, p.72), esquecer que outros povos lembram é um mecanismo para deixá-los esquecidos. Ironicamente, continua Fabian, esquecer que outros povos lembram é um risco premente justamente nos estudos de tradições orais, pois tais tradições só são levadas em conta enquanto correspondam ao mesmo tratamento metodológico dado às fontes escritas. Além do mais, nossa preocupação não deveria ser com o conteúdo esquecido, e sim com a lembrança e o esquecimento como aspectos concomitantes do trabalho da memória como práxis cultural (Fabian, 2007, p.82).

A constatação de Fabian é fundamental não só por expor o (recorrente) etnocentrismo, mas especialmente por apontar para um problema metodológico que consiste no pouco preparo em identificar (ou seria melhor dizer levar realmente a sério?) distintas formas de lembrar. De acordo com Finnegan (1992), os estudos das formas orais não se caracterizam por uma terminologia comum ou claramente delimitada, mas pelo conjunto de questões que atraem o foco investigativo dos pesquisadores. $\mathrm{O}$ interesse deve recair, portanto, nas formas de lembrar - que não se limitam apenas à verbalização, incluindo músicas e cantos, imagens visuais, práticas corporais, performances, rituais etc. A maneira de escapar à avaliação da oralidade em função do escrito parece-me ser inserir os relatos orais no interior das formas de lembrar e do trabalho da memória específicos (não exclusivos, note-se bem) a Cambará.

Um primeiro ponto a chamar atenção é que lembrança e esquecimento são aspectos concomitantes do trabalho da memória. Esquecer não remete necessariamente a uma carência. Num famoso conto, Borges recorda a história de um personagem dotado de uma rara capacidade de memorização, Funes. Recordações que sozinho teve-as mais que todos os homens, a memória de Funes é um despejadouro de lixos, pois é incapaz de esquecer diferenças, generalizar e abstrair. Os rastros do passado respondem antes a um trabalho de seleção e fixação de relevância do que a uma incapacidade. Com o tempo foi ficando evidente para mim que minha pergunta devia ser por que lembrar determinado evento, e não outro, é importante para os membros do grupo, e não pelas suas limitações mnemônicas.

Acresce que calar não significa esquecer. "Nós não esquecemos, apenas não lembramos", diz outro personagem da ficção - dessa vez de um romance de Mia Couto - a um antropólogo que o inquiria sobre determinados assuntos. $\mathrm{O}$ dito às vezes é tão importante quanto o não dito, como nos ensinou Pollak (1989). Em Cambará, as histórias sobre o "tempo do cativeiro" ilustram particularmente isso. Habitando zonas de silêncio, há um permanente cuidado com as palavras que se reflete na sua forma e capacidade de recuperar, de forma mais extensa e detalhada, histórias e personagens. Admitir que um "antigo" ou parente foi escravo pode ser não só indesejado, mas também evitado, especialmente quando se trata dos terrores indizíveis vividos, sofridos e infligidos durante a escravidão (Gilroy, 2001) ou das histórias para não se passar adiante, admiravelmente retratadas no romance Amada, de Toni Morrison ${ }^{6}$.

Essa dinâmica entre contar e não-contar é presente em outra esfera. Em Cambará, certas pessoas são apontadas como "sabedoras" do "tempo dos antigos". A idade é importante fator na definição de alguém como "sabedor", mas não só. Os eventos marcantes na história do grupo são de conhecimento geral, mas apenas algumas pessoas sabem contar. $\mathrm{Ou}$ seja, não basta conhecer ou ser velho, é necessário dominar técnicas que permitam transmitir o conteúdo narrado. Como nota Gallois (1993, p.26), a transmissão oral não precisa ser completa, nem a descrição exaustiva. Ela depende de uma forma de "transmissão participante". O interesse do narrador, na relação com o ouvinte, é conservar o que foi narrado. Ao retirar da sua experiência o que ele conta, o narrador incorpora as coisas narradas à experiência de seus ouvintes (Benjamin, 1996). Essa incorporação da coisa narrada depende, sobremodo, da incorporação da história no corpo do narrador. 
Ao narrar um "causo" que envolve um "antigo", reproduz-se suas falas, seus gestos, seus atos, suas expressões. Na narração, os hábitos de contar não são somente competências técnicas, mas atividades adquiridas, como nota Connerton (1993, p.112). Saber contar exige habilidades na maneira de contar, supõe o domínio de envolver os ouvintes nas coisas narradas. Os gestos, a entonação, as pausas e digressões dão formato ao conteúdo narrado. A reencenação dos eventos protagonizados pelos "antigos" é uma forma de transmitir o vivido do grupo e de estabelecer padrões de relevância do passado.

Ao enfocar as práticas corporais chamei atenção para a relação entre narrador e ouvinte. Há outro aspecto a explorar nesse último tocante e que pode ser exemplificado pelo momento que Cambará vive atualmente. A ênfase na relação do narrador com a platéia permitiu a alguns pesquisadores dissipar as abordagens que enxergavam as "tradições orais" como fixas (Finnegan, 1992). As artes verbais devem ser estudadas em seu contexto de produção, e não como manifestação de uma tradição acabada (Bauman e Sherzer, 1975; Tedlock, 1983). Assim, o conteúdo narrado depende de quem fala e para quem se fala.

No caso de Cambará é fundamental reter este ponto. O reconhecimento como comunidade remanescente de quilombo fez com que o grupo interagisse cada vez mais com agentes de diversos campos do mundo social. Na "luta" pela terra e por direitos étnicos, os moradores de Cambará se vêem constantemente às voltas com a necessidade de justificar seu status de grupo etnicamente diferenciado. Se o que caracteriza a identidade étnica face outras identidades sociais é o fato dela estar voltada para o passado (Streiff-Fenart; Poutignat, 1997), a "viagem da volta" (Oliveira, 1998; 1999) não é um exercício nostálgico de retorno ao passado e desconectado do presente (por esse motivo não é uma viagem de volta).

Isso fica particularmente sinalizado pela atuação da liderança do grupo, Márcio Lopes. No início da pesquisa com vistas à elaboração do laudo, ele já dispunha de páginas e páginas de seus cadernos preenchidos com genealogias, nomes de antigos moradores e informações históricas sobre a sucessão territorial na região. Certa feita elaborou, em um papel pardo, um croqui da região. $\mathrm{O}$ croqui primava pelo detalhamento. Constava o território ocupado no pretérito pelos "bem antigos". Os lotes e o campo de cada família que ali habitava hoje estavam discriminados. Ao lado do nome dos atuais ocupantes, trazia informações sobre a transmissão das terras, enumerava o nome dos antigos habitantes, estabelecia nexos genealógicos, pontuava a chegada dos brancos, apontava as taperas. Márcio já dispunha de tamanho volume de anotações que pensava em fazer uma espécie de arquivo da história da comunidade em sua casa.

Noutra ocasião, realizou um trabalho similar com base num mapa feito pelos geógrafos que compunham a equipe do laudo. Dizia que se havia acostumado a fazer esse tipo de pesquisa com os antigos. Disse-me que aprendera a desenvolver uma "técnica antropológica" para entrevistar os mais velhos. Era necessário ir com calma, respeitar as características pessoais de cada um, saber como e quando perguntar. Relatou as admoestações de seu pai, Geraldo, grande conhecedor dos antigos, pela insistência do filho em saber coisas que já haviam sido ditas. Foi "entrevistando" os mais velhos que Márcio Lopes coletou o material para suas genealogias e a elaboração do croqui.

Pode-se argumentar que a mobilização e a dedicação de Márcio atestam a formação de novas disposições em função da situação de reivindicação étnica do grupo. É pouco provável que manifestasse esse crescente interesse pela história de Cambará se não fosse o contexto atual. Talvez não empregasse suas forças e despendesse seu tempo em tal empreitada se a mobilização pela titulação das terras não tivesse lugar. Ademais, Márcio estava e está acionando novos meios de transmissão do passado. Ou seja, se os mais velhos transmitem lembranças oralmente e não fixam o território em documentos, Márcio está organizando um arquivo escrito sobre Cambará e fixando e visualizando em um mapa o território do grupo.

Esse quadro, contanto, é demasiado simplista, pois negligencia três aspectos fundamentais. Em primeiro lugar, não reduzo as narrativas dos membros de Cambará a uma mera adequação ao presente. Se a situação histórica do grupo certamente influi na dinâmica e reconfigurações do passado, é necessário tomar o cuidado de não redundar num circunstancialismo. Cabe pensar se nossa ânsia em decretar a inexistência das coisas não acaba por menosprezar as determinações do passado no presente (Santos, 2003). Afastemos mal-entendidos. Ao falar em determinações do passado não quero remeter ao acabado. Quero abrir um espaço de interrogação que não subordina o passado vivido exclusivamente ao reconstruído nas interações no presente.

O modelo da "invenção das tradições" (Hobsbawm; Ranger, 1997) parece-me insuficiente justamente por conta disso. O passado nunca permanece idêntico a si mesmo, mas ele é criado com base numa experiência vivida. As pessoas não se recordam a partir do nada; elas criam com base em um repertório. Ao enfatizar somente a dimensão política da etnicidade e as reelaborações da memória com vistas a legitimar a luta por direitos, corre-se o risco de tomar o tempo como máximo rendimento, ou seja, mero instrumento de realização de um ulterior distante (Tedesco, 2004, p.107-8).

Em segundo lugar, a documentação de uma história transmitida oralmente não é um ato de inauguração da escrita no interior do grupo. Embora praticamente todas as pessoas da comunidade nascidas entre 1910-1950 sejam analfabetas, elas já possuíam um contato com a escrita, mesmo que de forma esporádica. 
A relação entre oralidade e letramento não consiste na sobreposição de uma forma de registro por outra, mas sim no complexo entrelaçamento entre ambas (Street, 2003; Rappaport, 1990; 1994).

Em terceiro lugar, croquis e arquivos escritos tornam-se novos suportes da memória pari passu aos suportes territoriais da memória. Recentemente perguntei a Márcio se havia tido muita dificuldade em fazer seu "mapa". Respondeu que não, que faria outro naquele mesmo instante, se preciso. O que fez foi estacar em um ponto próximo à sua casa e esboçar o "mapa da comunidade". Disse-me que conhecia bem o lugar, por isso não tivera dificuldades. Essa história incrustada na paisagem foi o que possibilitou inscrever lembranças em um croqui.

Em sua já clássica obra, Rosaldo (1980) chama atenção para diferentes formas de evidências factuais intimamente relacionadas às percepções do espaço e do tempo. No grupo estudado por Rosaldo, os aspectos da natureza são como fontes documentais. As árvores, por elas mesmas, testemunham a verdade das histórias de residência passada. De igual modo, em Cambará, as regressões ao passado estão meticulosamente mapeadas nas paisagens. As paisagens, incorporadas nas histórias, conformam o que Rosaldo chama de "espacialização do tempo". O tempo é pensado em termos de sua configuração espacial.

A escolha dos lugares não é fortuita; corresponde aos itinerários do grupo. Os lugares são tempo de marcação de um tempo vivido, como nota Godoi (1999). O croqui de Márcio é apenas uma faceta dessa memória territorializada. Como diz Mia Couto em um de seus belos livros, a terra tem suas páginas: os caminhos. Isso fica particularmente sinalizado nos passeios que realizamos com os membros do grupo. A visualização da "morada dos antigos", dos "arvoredos" e "matos", das "divisas", das sangas, lagos e córregos, do salão de bailes e outros tantos lugares são os pontos de apoio da memória. Apontar onde um parente ou "antigo" viveu, plantou e trabalhou é uma forma de inscrever as relações familiares na história do grupo. Esse tempo genealógico estruturante da continuidade do grupo (Godoi, 1999) é mapeado meticulosamente na paisagem. Ao definir o que é seu território, os moradores de Cambará mobilizam e são mobilizados por sua história.

\section{Histórias obliteradas}

Iniciei este artigo perguntando pelos efeitos de conhecimento gerados pelas experiências e encontros etnográficos com o campo na relação estabelecida com $\mathrm{o}$ arquivo. Fiz menção, num primeiro momento, à si- tuação prática em que essa relação se deu. A pesquisa que resultou no laudo antropológico intentou valorizar a oralidade, mas esse exercício teve limitações impostas pelo gênero de saber que estávamos produzindo. Em seguida, ao expor de forma muito sumária alguns aspectos das formas de lembrar e do trabalho da memória existentes em Cambará, tentei lembrar que se lembra, independentemente da correspondência com o escrito. Argumentei que só é possível reduzir a assimetria entre oral/escrito tomando a oralidade em seus próprios termos.

Não se trata tanto de um relativismo complacente. $\mathrm{O}$ caso da oralidade exemplifica bem a tendência da antropologia em deslizar entre o culturalmente razoável e o conforme a razão sem muitas problematizações. Para ser mais preciso, supõe-se diferentes princípios cognitivos em funcionamento, passando-se sem mediação das representações culturais aos processos de pensamento (Fausto, 2001, p.492). Ao invés de propor uma interpretação sobre o modo de pensar indígena, talvez fosse interessante realizar uma experimentação com ele e, portanto, com o nosso (Viveiros de Castro, 2002, p.123-4).

A assimetria entre oral e escrito é mantida, sustentada e erigida não só pelo esquecer que se lembra, mas sobretudo pela redução da criatividade de outras culturas à nossa realidade (Wagner, 1981). Enquanto avaliarmos os relatos orais como formas imperfeitas e inacabadas de registro do passado, continuaremos a reduzir novas potencialidades e possibilidades de viver a vida aos termos de nossas ideologias. Ao invés de estabelecermos uma relação de conhecimento que permita a emergência de mundos possíveis, procedemos a uma alegoria das discriminações que operamos no nosso diaa-dia. Nas sociedades ocidentais, a história é encarnada e vivida em lugares da memória como o arquivo.

Como nota Nora (1984), vivemos numa era ansiosa por conservar. A distinção entre memória e história proposta pelo autor refere à constituição gigantesca e vertiginosa de suportes materiais do passado. Menos a memória é vivida do interior, mais ela necessita de suportes exteriores. Daí a obsessão pela preservação integral do passado. "Há lugares da memória porque não há mais meios de memória", diz o autor francês (Nora, 1984, p.23). Rede que mobiliza uma enorme amplitude de humanos e não-humanos, os lugares da memória definem o trabalho de instrumentação que oferece os padrões de medida e comensurabilidade entre sociedades (Latour, 1994). Os artefatos do arquivo são pensados menos como suportes mnemônicos e mais como repositórios de um passado pronto a ser desvendado pela autoridade do documento ${ }^{7}$. Será que a ausência de repositórios gigantescos de conservação do passado manifesta ca- 
rências mnemônicas ou revela formas diferenciadas de viver, conviver e interpretá-lo?

Como faz notar Cunha (2005), o Arquivo é um campo igualmente marcado pelos encontros e relações diversas de conhecimento. Se há uma historicidade própria aos artefatos (como o documento, por exemplo) capturados por etnógrafos e historiadores - eles também possuem a sua história - é necessário mover a atenção para o estatuto desses artefatos e sua (suposta) capacidade de remeter-nos a um passado:

$\mathrm{O}$ valor do documento reside em que se mantenha intacto na sua suposta capacidade de nos deslocar para o passado. Para tanto, quase sempre, serve de atestado, prova material de que o que o tempo, pelo menos naquele objeto, foi preservado. Em diversos encontros aprendi ser possível 'ver' outras coisas: o tempo que permanece transformado (Cunha, 2005, p.26 [grifos no original]).

A antropologia simétrica proposta por Latour (1994) e antropologia reversa de Wagner (1981) constituem aportes inovadores ao deslocarem o foco de atenção para os efeitos reflexivos que as experiências e experimentações com o "pensamento nativo" podem exercer nas nossas práticas de conhecimento. Os relatos e lembranças dos moradores de Cambará permitiram-me estabelecer uma relação em outros termos com o arquivo. Os eventos que emergiam dos documentos eram especialmente enriquecidos pela forma que eu confrontava o passado e a forma pela qual o passado me confrontava. O documento remetia-me a um passado. A diferença é que o mosaico que o compunha estava povoado por vozes: as vozes dos narradores e narradoras de Cambará.

$\mathrm{O}$ registro de transmissão de terras revelava padrões de acesso a terra, estatísticas fundiárias, a correlação entre capital fundiário e ocupação territorial, mas também uma dramaticidade da existência. Os locais apontados em mapas, medições e registros fundiários eram menos uma localização geográfica, e mais um palco onde pessoas construíram suas casas, freqüentaram festas, trabalharam sua lavoura, criaram seus filhos, plantaram árvores. A escritura de compra e venda estava circundada por outras versões, outras visões do fato. Por trás de termos regimentais, afiguravam-se meandros ausentes na memória oficial, mas que estavam presentes hoje, no presente cotidiano do grupo. Uma alforria remetia para as políticas de liberdade de certo período. Mas remetia também a um "causo" protagonizado pelo beneficiário dela. Muitos documentos tratavam de eventos protagonizados por pessoas que eu conhecia por meio de relatos. Nesses encontros com o arquivo, visualizava os gestos, as expressões, as reações e falas dessas pessoas filtradas pelos narradores do presente.

A produção de um texto descritivo sobre esses encontros tornou-se o registro de várias historicida- des: a dos artefatos que capturam o tempo, a das memórias e lembranças compartilhadas em um momento específico e àquela produzida pela narrativa antropológica. São esses diferentes encontros e relações de conhecimento que descortinam outras possibilidades na produção de uma narrativa sobre o passado. O passado compartilhado entre homens e mulheres de Cambará com pesquisadores traz a possibilidade de trazer à lembrança memórias e narrativas que estão ausentes justamente nos espaços e lugares repositórios do passado.

Não estou supondo que os relatos remetam "aquilo que de fato aconteceu". Tampouco que sejam versões estáticas e intactas - o exemplo de Márcio demonstra o contrário. O que está em jogo não é um essencialismo, mas um pluralismo. Um dos potenciais da chamada história oral consiste justamente em oferecer novos temas e problemas à história, não desconhecê-la. Há uma tendência nos trabalhos antropológicos dedicados à realização de laudos em tomar a história oral como substituta dos documentos, reclamando para si uma materialidade, validade e exclusividade que o universo escrito e histórico sempre reservou para si. O problema consiste na substituição de um substancialismo por outro, como nota Arruti (2005, p.124-5).

Esse perigo só se apresenta se tomarmos a oralidade exclusivamente como fonte ou metodologia. Pensar a oralidade além da metodologia (Amado; Ferreira, 1996) e da fonte histórica (Vansina, 1985; Thompson, 1992; Prins, 1992) permite perguntar por outras coisas, estabelecer novas relações de conhecimento. As mediações com os arquivos, permeadas por relatos orais podem descentrar o estatuto do documento (artefato) e localizá-lo não como um simples retorno ao pretérito. Antes, um retorno que também é mediado, que segue padrões de relevância de fixação e não-fixação dos eventos. Ao eleger o documento como locus privilegiado de reconstituição do passado, outras histórias e outras memórias restam obliteradas. Os efeitos de conhecimento podem ter grande valia não tanto por apresentar uma versão "mais verdadeira" do que a oferecida pelo Arquivo, mas por apresentar outras possibilidades de apreender o passado.

A conjugação campo-arquivo traz efeitos reflexivos sobre as avaliações e concepções que fazemos dos nossos dados e das concepções que balizam nossas reconstruções históricas. Se o acervo documental nos auxilia na compreensão de determinados aspectos de Cambará, por outro lado as concepções dos membros de Cambará sobre a história permitem pensar em outro patamar os documentos, exercendo efeitos de conhecimento na leitura e reconstrução do passado. Como nota Trouillot (1995), o silenciamento do passado inerente à produção histórica não é anulado pelo aumento do escopo de fontes, simplesmente. A grande questão parece ser que tipo de pergunta se faz às fontes. Talvez pudéssemos procurar o não-dito do dito. Pensar os diferentes 
tempos subsumidos num tempo cronológico. Atentar para as políticas do tempo (Fabian, 1983) e sua conjugação com as instituições e espaços tidos por repositórios do tempo. Pensar, sobretudo, naquilo que fica às bordas das grandes narrativas pelo discurso oficial e pelas próprias práticas do fazer científico.

\section{Referências}

ANJOS, José Carlos Gomes dos. "Remanescentes de Quilombos: reflexões epistemológicas". In: LEITE, Ilka Boaventura (Org.). Laudos Periciais Antropológicos em Debate. Florianópolis: Nova Letra/NUER, 2005. p.89112 .

ANJOS, José Carlos Gomes dos; SILVA, Sergio Baptista da. São Miguel e Rincão dos Martimianos. Territorialidade e Ancestralidade Negra. Porto Alegre: Ed. da UFRGS/ FCP, 2004.

ARRUTI, José Maurício. "Etnografia e História no Mocambo: notas sobre uma situação de perícia". In: LEITE, Ilka Boaventura (Org.). Laudos Periciais Antropológicos em Debate. Florianópolis: Nova Letra/NUER, 2005. p.113-137.

BAUMAN, Richard; SHERZER, Joel. The Ethnography of Speaking. In: Annual Review of Anthropology, v.4, 1975. pp.95-119.

BENJAMIN, Walter. “O Narrador”. In: Obras Escolhidas I. São Paulo: Brasiliense, 1996.

CONNERTON, Paul. Como as Sociedades Recordam. Oeiras: Celta Editorial, 1993.

CUNHA, Olívia Maria Gomes da. "Do ponto de vista de quem? Olhares, diálogos e etnografias dos/nos arquivos". In: Revista de Estudos Históricos, Rio de Janeiro, v. 36, p. 7-32, 2005.

FABIAN, Johannes. Time and the Other. How anthropology makes its object. New York: Columbia university press, 1983

FABIAN, Johannes. Memory against Culture. Arguments and reminders. Durham: Duke University Press, 2007.

FAUSTO, Carlos. Inimigos Fiéis. História, Guerra e Xamanismo. São Paulo: Edusp, 2001.

FINNEGAN, Ruth. Oral Traditions and the Verbal Arts: A guide to research practices. New York: Routledge, 1992.

FOUCAULT, Michel. A Arqueologia do Saber. 7. ed. Rio de Janeiro: Forense Universitária, 2003 [1969].

GALLOIS, Dominique. Mairi Revisitada: A reintegração da Fortaleza de Macapá na tradição oral dos Waiãpi. São Paulo: FAPESP, 1993

GILROY, Paul. O Atlântico Negro: Modernidade e dupla consciência. São Paulo: Editora 34, 2001 [1993].

GODOI, Emília P. O Trabalho da Memória: Cotidiano e história no Sertão do Piauí. Campinas: ed.Unicamp, 1999.

GOLDMAN, Márcio; LIMA, Tânia S. "Como se faz um grande divisor?” In: GOLDMAN, Márcio. Alguma Antropologia. Rio de Janeiro: relume-dumará, 1999.

GOODY, Jack. La Domesticación del Pensamiento Selvage. Madrid: Akal editor, 1985.

GOODY, Jack. A Lógica da Escrita e a Organização da Sociedade. Lisboa: Edições 70, 1987.

HOBSBAWM, Eric; RANGER, Terence. "Introdução". In: A Invenção das Tradições. Rio de Janeiro: Paz e Terra, 1997 [1983].
LATOUR, Bruno. Jamais Fomos Modernos: ensaios em antropologia simétrica. São Paulo: Editora 34, 1994.

MATTOS, Hebe e RIOS, Ana L. Memórias do Cativeiro: família, trabalho e cidadania. Rio de Janeiro: Civilização Brasileira, 2005.

NORA, Pierre. "Entre Mémoire et Histoire. La problematique des lieux". In: NORA, Peirre (ed.). Les Lieux de Mémoire. Paris: Gallimard, 1984. p.23-43.

OLIVEIRA, João Pacheco de. Uma Etnologia dos 'Índios Misturados'? Situação colonial, territorialização e fluxos culturais. Mana - Estudos de Antropologia Social, Rio de Janeiro, v.4, n.1, 1998. p.47-77.

OLIVEIRA, João Pacheco de. A Viagem da Volta: etnicidade, política, e reelaboração cultural no Nordeste indígena. Rio de Janeiro: Contracapa, 1999.

OLIVEIRA, João Pacheco de. "O Antropólogo como Perito: entre indianismo e o indigenismo". In: L'ESTOILE, Benoît; NEIBURG, Federico; SIGAUD, Lygia (Orgs.). Antropologia, Impérios e Estados Nacionais. Rio de Janeiro: Relumé Dumará/FAPERJ, 2002. p.253-277.

ONG, Walter. Oralidade e Cultura Escrita: a tecnologização da palavra. Campinas: Papirus, 1998.

POLLAK, Michael. "Memória, Esquecimento, Silêncio". Estudos Históricos, Rio de Janeiro, vol.2, n.3, 1989. p.315.

PRICE, Richard. First-Time. The historical vision of an Afro-American People. Baltimore and London: John Hompkins University Press, 1983.

PRICE, Richard. Alabi's World. Baltimore: John Hopkins University Press, 1990.

PRICE, Richard. "Palmares como poderia ter sido". In: REIS, João José; GOMES, Flávio Santos (Orgs.) Liberdade por um Fio: história dos quilombos no Brasil. São Paulo: Companhia das Letras, 1996. p.52-59.

PRINS, Gwyn. "História Oral". In: BURKE, Peter (Org.). A Escrita da História. Novas perspectivas. São Paulo: unesp, 1992, p.163-198.

RAPPAPORT, Joanne. The Politics of Memory. Native historical interpretation in the Colombian Andes. Cambridge: Cambridge University Press, 1990.

RAPPAPORT, Joanne. Cumbe Reborn. An Andean ethnography of History. Chicago: Chicago University Press, 1994.

ROSALDO, Renato. Ilongot HeadHunting. Essays on Society and History. Stanford: Stanford University Press, 1980.

SANTOS, Myrian Sepúlveda dos. Memória Coletiva e Teoria Social. São Paulo: Annablume, 2003.

STREET, Bryan. What's 'new' in New Literacy Studies? Critical approaches to literacy in theory and practice. Current Issues in Comparative Education, v.5, n.2, 2003 , p.77-91.

STREIFF-FENART, Jocelyne e POUTIGNAT, Philippe. Teorias da Etnicidade. São Paulo: Unesp, 1997. 
TEDESCO, João Carlos. Nas Cercanias da Memória. Temporalidade, experiência e narração. Passo Fundo: UPF, 2004.

TEDLOCK, Dennis. The Spoken World and the Work of Interpretation. Philadelphia: University of Pennsylvania Press, 1983.

THOMPSON, Paul. A Voz do Passado. História Oral. Rio de Janeiro: Paz e Terra, 1992.
TROUILLOT, Michel-Rolph. Silencing the Past. Power and Production of History. Boston: Beacon Press, 1995.

VANSINA, Jan. Oral Tradition as History. Madison: University of Wisconsin Press, 1985.

VIVEIROS DE CASTRO, Eduardo. O Nativo Relativo. Mana-Estudos de Antropologia Social. Rio de Janeiro. v. 8 n.1, 2002. p.113-146.

WAGNER, Roy. The Invention of Culture. (2. ed.) Chicago: Chicago University Press, 1981.

\section{Mutations of the eye: the dialogue between the field and the files}

\section{Abstract}

The goal of this paper is to reflect on the use of written sources in anthropological research and its relationship with the ethnographic production, as well as the involvement of field experiences in the description, management and reading of these sources. This paper discloses the different contexts of the field and file researches involving the black rural community of Cambará, which is located between the towns of Cachoeira do Sul and Caçapava do Sul (Rio Grande do Sul). It is considered that only taking the orality in their own terms - through the description of the ways of remembering and the work of memory - it is possible to reduce the asymmetry between oral and written languages. It is argued that the oral reports collected in the field may have effects of knowledge in reading from written sources and putting new issues for the reconstruction of the historical past.

Key-words: Africa; immigrant; narrative; culture; itinerary.

Data de recebimento do artigo: 15 de fevereiro de 2008

Data de aprovação do artigo: 22 de abril de 2008 